\title{
Electrochemical Investigation of Corrosion on AISI 316 Stainless Steel and AISI 1010 Carbon Steel: Study of the Behaviour of Imidazole and Benzimidazole as Corrosion Inhibitors
}

\author{
Roberta R. Moreira, Thiago F. Soares, Josimar Ribeiro* \\ Department of Chemistry, Federal University of Espírito Santo, Vitória, Brazil \\ Email: ${ }^{*}$ josimar.ribeiro@ufes.br
}

Received 22 August 2014; revised 15 September 2014; accepted 30 September 2014

Copyright @ 2014 by authors and Scientific Research Publishing Inc.

This work is licensed under the Creative Commons Attribution International License (CC BY).

http://creativecommons.org/licenses/by/4.0/

(c) () Open Access

\begin{abstract}
An electrochemical investigation of the corrosion on AISI 316 austenitic stainless steel and AISI 1010 carbon steel in sodium chloride solution (3.0 wt.\%) was performed in the absence and presence of imidazole and benzimidazole corrosion inhibitors. The results showed that at any inhibitor concentration (25 ppm to $1000 \mathrm{ppm})$, there was an increase in the polarisation resistance of both steels. The highest efficiency of corrosion inhibition was obtained using imidazole at a concentration of 50 ppm for both steels, with values of $96 \%$ for the AISI 316 stainless steel and $73 \%$ for the AISI 1010 carbon steel.
\end{abstract}

\section{Keywords}

Stainless Steel, Carbon Steel, Polarisation, Anodic Dissolution, Inhibition

\section{Introduction}

Corrosion as a destructive phenomenon incurs a high cost to the economy and society. The costs have been estimated to be as high as 5\% of GDP in many developed countries [1] [2]. All metallic material can undergo different types of degradation processes when exposed to different environmental conditions, either by natural factors or by industrial or other human activities [3]. Corrosion can affect critical areas or regions of a material and

\footnotetext{
*Corresponding author.
}

How to cite this paper: Moreira, R.R., Soares, T.F. and Ribeiro, J. (2014) Electrochemical Investigation of Corrosion on AISI 316 Stainless Steel and AISI 1010 Carbon Steel: Study of the Behaviour of Imidazole and Benzimidazole as Corrosion Inhibitors. Advances in Chemical Engineering and Science, 4, 503-514. http://dx.doi.org/10.4236/aces.2014.44052 
thereby modify its true functionality [4]. Additionally, the lifetime of metallic equipment tends to decrease further in more aggressive environments [1].

In coastal regions, the corrosion of steel infrastructure can have considerable negative effects, and due to the high costs of maintenance and corrosion protection measures, there is interest in applying increasingly resistant steels [5]. According to Tsutsumi et al. [6], sea water is an aggressive environment that affects almost all structural materials. Present in the composition of sea water are salts such as $\mathrm{NaCl}$ and $\mathrm{MgCl}_{2}$, which are primary agents responsible for localised corrosion. The chloride ion is the most common in marine environments and the main cause of the breakdown of the passive film on steels [7] [8]. The presence or absence of this protective film on the surface of metals is responsible for controlling the behaviour of corrosion because of its action as a protective barrier against corrosion attacks [4] [9].

Several metals suffer pitting corrosion when exposed to solutions with high chloride content [10]. Pitting corrosion is characterised by a process of localised metal dissolution that affects the integrity of the metal and, in some cases, leads to catastrophic failure. Although this form of corrosion occurs only in small areas of the metal surface, it remains a major concern due to its fast attack and penetration inside the metal [11] [12].

The increased use of stainless steel has contributed substantially to the economic development of many countries. For decades, it has been used structurally in architectural elements such as beams and arches in bridges [13].

In the case of stainless steel in contact with seawater, the corrosion rate and pitting potential depend on the levels of $\mathrm{Cr}$ and $\mathrm{Ni}$ present in the steel. The presence of Co, Mo and $\mathrm{N}$ has a significant influence on the corrosion resistance [14]. Austenitic stainless steels, whose main alloying elements are chromium and nickel, are considered to have high corrosion resistance in most environments compared with ferritic and martensitic steels [15]. The AISI 316 stainless steel, specifically, is perhaps one of the most used steels, after carbon steel, serving a structural material in industrial plants in marine environments, including desalination plants [14]. Carbon steel is also widely used in systems that operate in land and marine environments [16] and is found in various applications in our everyday life due to its relatively low cost [17].

To preserve the integrity of metallic materials, some measures to inhibit or prevent corrosion in many aggressive media are cited in the literature [4] [18]. Organic inhibitors that exhibit one or more polar functions (such as $\mathrm{N}, \mathrm{O}$ and $\mathrm{S}$ ) and heterocyclic compounds with polar groups and $\pi$ electrons have been quite effective in corrosion protection [19]. This inhibition efficiency is usually attributed to the specific interactions that occur between functional groups and heteroatoms with the metal surface due to their lone pair electrons [20] and the influence on the change of corrosion potential [20] [21]. Certain organic compounds, such as thiophene derivatives, were studied as corrosion inhibitors for AISI 316 stainless steel in acid media with chloride ions and resulted in an efficiency of approximately 97\% [22]. According to studies conducted by Farahani and Goudarzi [23], a benzothiazole derivative was also efficient in inhibiting the corrosion of AISI 316 stainless steel in an acid medium.

With respect to AISI 1010 carbon steel, a compound commercially known as Dodigen, which is a mixture of amines and amides, was studied as a corrosion inhibitor by Granero et al. [24]. The authors found that Dodigen had an efficiency ranging from $74 \%$ to $98 \%$, depending on the concentration used. Other investigations using computer simulations of new imidazole derivatives showed that these compounds possess the ability to inhibit the corrosion process on AISI 1010 carbon steel, which showed 62.8\% inhibition efficiency [25].

Other organic inhibitors such as benzimidazole and its derivatives have been reported in the literature as effective corrosion inhibitors with structural features that allow adsorption to the metal surface [26] [27]. Benzimidazole, an imidazole derivative, is an organic compound that has aromaticity and nitrogen heteroatoms with lone pair electrons, which facilitate the adsorption to the metal [27]-[29]. Studies have shown that it provides a high corrosion inhibition ability to copper in acidic, neutral and alkaline media [26] and to carbon steel in acidic medium [30].

Imidazole and its derivatives have been used as corrosion inhibitors for various metals and alloys [30]-[33]. The advantages of imidazole, including that it does not have a detrimental effect on the environment and its convenience and low cost, have made the use of these compounds very attractive [32]-[37]. Imidazole is a planar organic five-membered aromatic heterocycle that has two nitrogen atoms [31]. The protective mechanism of this molecule to the surface of the metallic material can occur via the adsorption of electron pairs isolated from the pyrrole nitrogen or parallel to the surface [36] of the imidazole ring.

This paper investigated the corrosion of AISI 316 austenitic stainless steel and AISI 1010 carbon steel in so- 
lutions containing $3.0 \mathrm{wt} \%$ chloride ions and the efficiency of corrosion inhibition of benzimidazole and imidazole inhibitors in different concentrations. The morphological and compositional analyses were performed by Laser-induced plasma emission spectroscopy (LIPS), X-ray diffraction (XRD), scanning electron microscopy (SEM) and energy dispersive X-ray (EDX), and the electrochemical study was performed by potentiodynamic polarisation.

\section{Experimental Section}

\subsection{Sample Preparation}

The samples used in this study were AISI 316 austenitic stainless steel, provided by Tecinox industry, and AISI 1010 carbon steel, provided by the Brazil Steel RDG; both companies are located in Espírito Santo, Brazil. The samples were prepared in two different ways. For morphological analysis, the samples were prepared in a square shape, with dimensions of $1.0 \mathrm{~cm} \times 1.0 \mathrm{~cm}$. For the electrochemical investigations, the samples were L-shaped, with dimensions of $3.0 \mathrm{~cm} \times 1.0 \mathrm{~cm}$. Each sample was prepared to leave an area of $1.0 \mathrm{~cm}^{2}$ to test, which was isolated with the aid of an epoxy resin (Araldite ${ }^{\circledR}$ ).

Before performing each analysis, the samples were subjected to cleaning and polishing of the surface using sandpaper of several different particle sizes in water, respectively, in the following order: 220, 320, 400, 600 and 1200 mesh. The polishing was finished with $0.3 \mu \mathrm{m}$ alumina to obtain a uniform surface. At each change of sanding, the sample was rotated $90^{\circ}$. The specimens were then washed with distilled water, degreased with acetone and dried with a hot air blast. Before and after every analysis, the samples were stored in argon to prevent contamination by contact with the external environment.

\subsection{Physico-Chemical Characterisation}

Laser-induced plasma emission spectroscopy using a Foundry-Master Pro spectrometer of the Shimadzu Corporation equipped with an Echelle optics and Kodak KAF 1001 ICCD detector allowed us to estimate the chemical composition of the alloys.

The XRD analyses were carried out on a Bruker model D8 Discover diffractometer operating with $\mathrm{Cu} \mathrm{K}_{\alpha}$ radiation $\left(\lambda=1.5406 \AA\right.$ ) generated at $40 \mathrm{kV}$ and $40 \mathrm{~mA} ; 2 \theta$ was scanned from $20^{\circ}$ to $100^{\circ}$ at a scan rate of $2^{\circ}$ $\min ^{-1}$. The EVA V3.1 software was used to process the XRD data.

Metallographic analysis was performed to reveal the microstructure of steels. A chemical attack was performed on the sample of AISI 316 austenitic stainless steel with $1: 3 \mathrm{HNO}_{3}: \mathrm{HCl}$ solution for 20 seconds to reveal the structure of the austenite grains and the presence of carbides. In the case of AISI 1010 carbon steel, 2\% Nital (98\% ethyl alcohol and 2\% nitric acid) was used as the attack solution for $15 \mathrm{~s}$ to reveal the grain boundaries of ferrite. Microstructural characterisation was performed using a Nikon Eclipse 200 MA optical microscope at 1000× magnification with polarised light. A Shimadzu SS550 scanning electron microscope coupled to an SEDX model analyser was used to investigate the corrosion morphology. The EDX results were obtained from the matrix interference, atomic number, absorbance, and fluorescence (ZAF correction) data. Between the electrochemical and morphological analyses, all of the samples were stored in argon atmosphere to avoid any outside contamination.

\subsection{Electrochemical Characterisation}

Electrochemical measurements were performed using a $100 \mathrm{~mL}$ capacity electrochemical cell with three electrodes. The reference electrode was $\mathrm{Ag} / \mathrm{AgCl}_{(\mathrm{KCl}, 3 \mathrm{~mol} / \mathrm{L})}$, the counter electrode was carbon with dimensions of 2.1 $\mathrm{cm} \times 0.5 \mathrm{~cm} \times 1.8 \mathrm{~cm}$, and the working electrode was made of AISI 316 austenitic stainless steel or AISI 1010 carbon steel. For electrochemical tests, a potentiostat/galvanostat AUTOLAB PGSTAT model 302N and GPES software were used. The corrosion tests were performed in duplicate using reagents to prepare solutions and analytical grade deionised water with a conductivity of $23.07 \mathrm{mS} \cdot \mathrm{cm}^{-1}$ at $25^{\circ} \mathrm{C}$ from a deioniser trademark of Union analysis. The temperature was monitored and remained at $24^{\circ} \mathrm{C} \pm 1.0^{\circ} \mathrm{C}$. The corrosive media used in the tests were composed of sodium chloride at $3.0 \mathrm{wt} \%$ using PA-Impex reagent ACS in the presence or absence of benzimidazole (Sigma-Aldrich, 98\%) and/or imidazole (Sigma-Aldrich, 98\%). Imidazole and benzimidazole were employed as corrosion inhibitors at different concentrations: 25, 50, 100, 500 and 1000 ppm. For Tafel polarisation measurements, the potential was varied by $\pm 250 \mathrm{mV}$ from the open circuit potential $\left(\mathrm{E}_{\text {ocp }}\right)$ at a scan 
rate of $0.5 \mathrm{mV} \cdot \mathrm{s}^{-1}$. $\mathrm{E}_{\text {ocp }}$ was obtained by measuring electrochemical noise and was measured until the system came into balance for a period of 4000 seconds.

\section{Results and Discussion}

\subsection{Laser-Induced Plasma Emission Spectroscopy (LIPS)}

Table 1 shows the results for the chemistry of the steels obtained via LIPS. The results obtained for the studied steels are within the composition range of AISI 316 [15] and AISI 1010 [38] as described in the literature.

\subsection{X-Ray Diffraction}

The XRD patterns of the analysed samples of AISI 316 stainless steel and AISI 1010 carbon steel are shown in Figure 1. The possible crystallographic phases present in each sample of steel and the orientation of these crystals can be observed. The XRD pattern of AISI 316 stainless steel shows diffraction peaks at $43.59^{\circ}, 74.65^{\circ}$ and $90.63^{\circ}$, relative to iron-nickel phase (FeNi) with reflection planes (111), (220) and (311), respectively, as the PDF-[01-077-7974]. A peak relative to chromium (Cr) phase with reflection plane (200) in accordance with the PDF-[01-088-2323] was observed at 50.78 . Both phases present have a face-centred cubic structure.

The XRD pattern of AISI 1010 carbon steel contains peaks that can be attributed to iron (Fe) present in a single phase composed of ferrite whose $2 \theta$ angles are $44.71^{\circ}, 65.08^{\circ}$ and $82.41^{\circ}$ with reflection planes (110), (200) and (211), respectively, as the PDF-[06-0696]. The observed phase structure is body-centred cubic.

\subsection{Physico-Chemical Investigation}

The metallography images of the studied steels are presented in Figure 2 and show the grain boundaries of the phases present in the steel and the presence of carbides. The image obtained for the AISI 316 steel (Figure 2(a)) shows that the chemical attack revealed the grain boundaries of the austenite phase grains of precipitated carbides and the presence of twinned boundaries, which is caused by the displacement of atoms in the lattice due to stress or heat treatment.

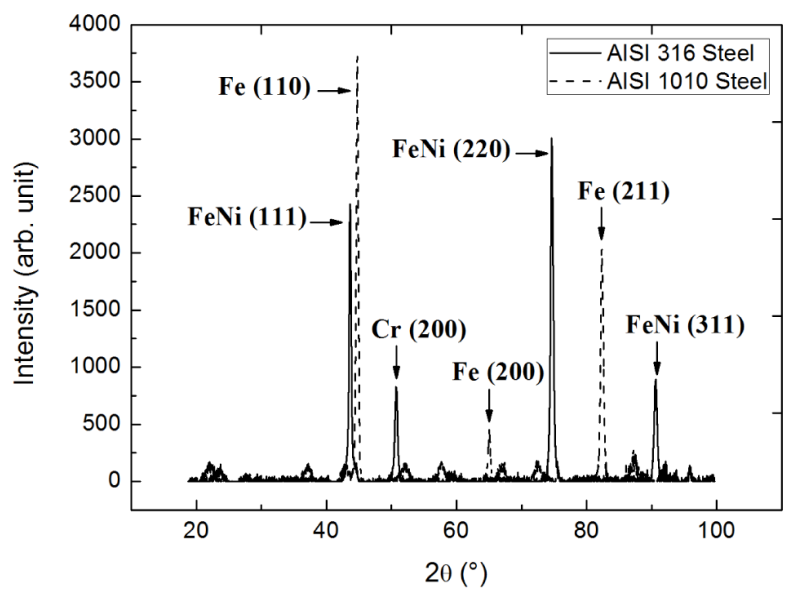

Figure 1. XRD pattern of AISI 316 stainless steel and AISI 1010 carbon steel.

Table 1. Chemical composition of AISI 316 austenitic stainless steel and AISI 1010 carbon steel.

\begin{tabular}{|c|c|c|c|c|c|c|c|c|}
\hline \multirow{2}{*}{ AISI } & \multicolumn{8}{|c|}{ Chemical Composition (wt\%) } \\
\hline & $\mathrm{C}$ & $\mathrm{Mn}$ & Si & $\mathrm{Cr}$ & Mo & $\mathrm{P}$ & $\mathrm{S}$ & $\mathrm{Ni}$ \\
\hline 316 & 0.0501 & 1.34 & 0.507 & 16.3 & 2.01 & 0.0278 & 0.0019 & 10.5 \\
\hline 1010 & 0.0954 & 0.351 & 0.0083 & 0.0238 & 0.0023 & 0.0150 & 0.0084 & 0.0074 \\
\hline
\end{tabular}



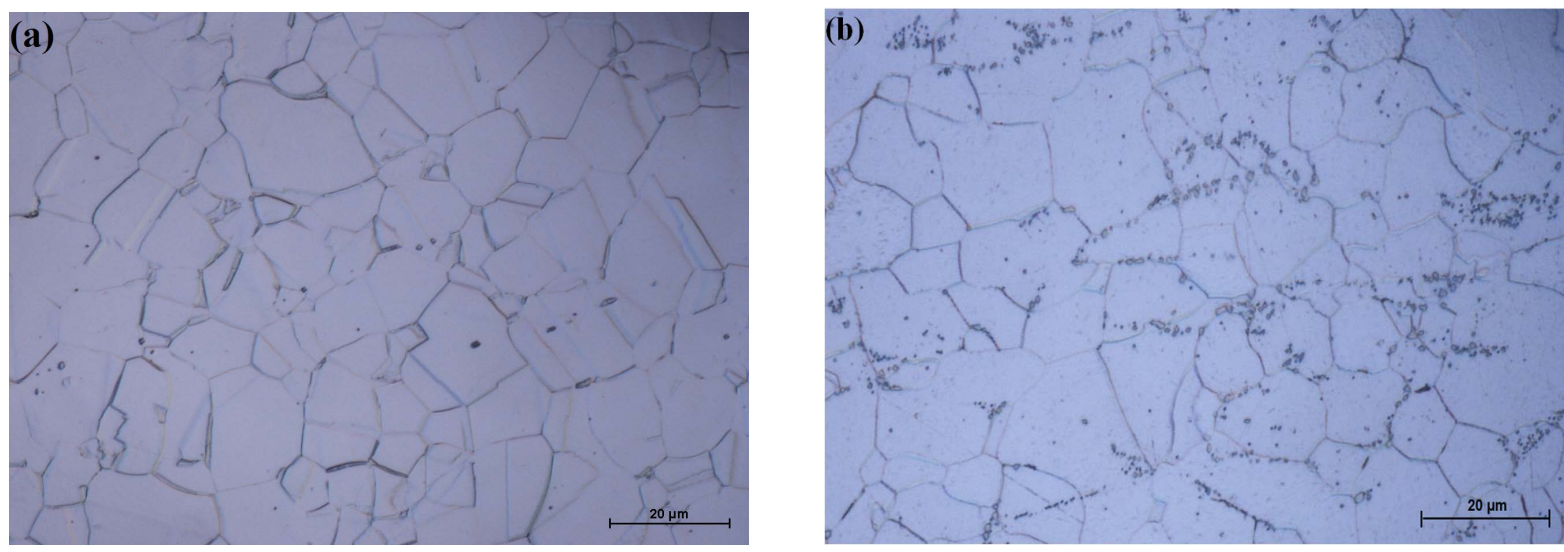

Figure 2. Metallographic images at $1000 \times$ magnification of the two grades of steel before the attack of chloride ions in solution. (a) AISI 316 stainless steel and (b) AISI 1010 carbon steel.

Similarly, the metallographic image of AISI 1010 steel (Figure 2(b)) revealed the grain boundaries present, which are composed of ferrite. Higher than the amounts of AISI 316 were also revealed that grain carbide steel, including regions of the grain boundary, which can be observed in Figure 2(b). Such regions, including the steel grain boundaries, deformation and non-metallic inclusions, have been found in the literature to be preferred sites for the occurrence of corrosion, particularly pitting corrosion [16] [39].

The scanning electron microscopy and EDX spectra of the steel before the etching process are shown in Figure 3. Nonmetallic inclusions are present in both of the steel samples studied. These inclusions are more prone to the start of an anodic attack in a corrosive environment, and these areas become the sites of nucleation of pitting [16] [39]. The difference in composition between regions of inclusions and the matrix of the steel is responsible for generating the potential difference in these two areas, which initiates the corrosion process.

The EDX analysis of AISI 316 (Figure 3(b)) stainless steel shows the elemental composition of the sample found in the possible inclusion of steel and the elemental composition of the matrix of the steel. From this analysis, it is observed that this inclusion in the AISI 316 steel is composed mostly of carbon and oxygen. The EDX analysis also shows peaks related to silicon, manganese, sulphur and chromium in lower content than the matrix, showing that it can accommodate Si and Cr oxides, as well as the presence of carbides and manganese sulphide. The presence of grains of carbides precipitated in the steel is in accordance with the analytical results of the inclusions performed using the metallography technique, as mentioned above.

Elements such as oxygen, sulphur, nitrogen, phosphorus, chlorine, sodium and potassium may exist in steel primarily as a result of the steel-making process and are responsible for generating negative effects on the properties of steels, causing brittleness and lower corrosion resistance. To reduce the amount of oxygen and sulphur in $\mathrm{Al}-\mathrm{Si}$ alloy, for example, elements are added in the metal degreasing process because of the strong reactivity of these elements to oxygen forming their oxides [40].

Figure 4 shows EDX spectra and micrographs of the steels after the corrosion process in a solution containing $3.0 \mathrm{wt} \%$ chloride ions. The SEM analysis of the surface of the steels after suffering corrosive attack by chloride ions allowed the identification of the type of corrosion that occurred on the surface of each of the steels. After analysing the image in Figure 4(a), which shows the surface of the AISI 316 steel after attack by chloride ions, the type of corrosion was identified as the pitting type, which is characterised by a larger corrosion depth than diameter and occurs in small, localised regions of the metal surface. However, the image that shows the AISI 1010 steel surface after attack by chloride ions (Figure 4(b)) reveals that there has been widespread and uniform corrosion on the steel surface because the corrosion is present across the extent of the surface and because the corrosion product exhibits porosity.

The corrosive attack of chloride ions to the AISI 316 steel was expected because pitting corrosion occurs in passive metals and steel in regions where there are flaws in the protective film, as observed in studies by Burstein and Pistorius [10], Kondo [11] and Turnbull et al. [12], and in deformed regions and non-metallic inclusions [16] [39]. This explanation is supported by SEM surface analysis and by EDX analysis of the pitting, which shows the presence of elements related to non-metallic inclusions (Figure 4(c)) and that this steel is susceptible to such corrosion characteristics. Conversely, because AISI 1010 steel is not passivated, the entire sur- 

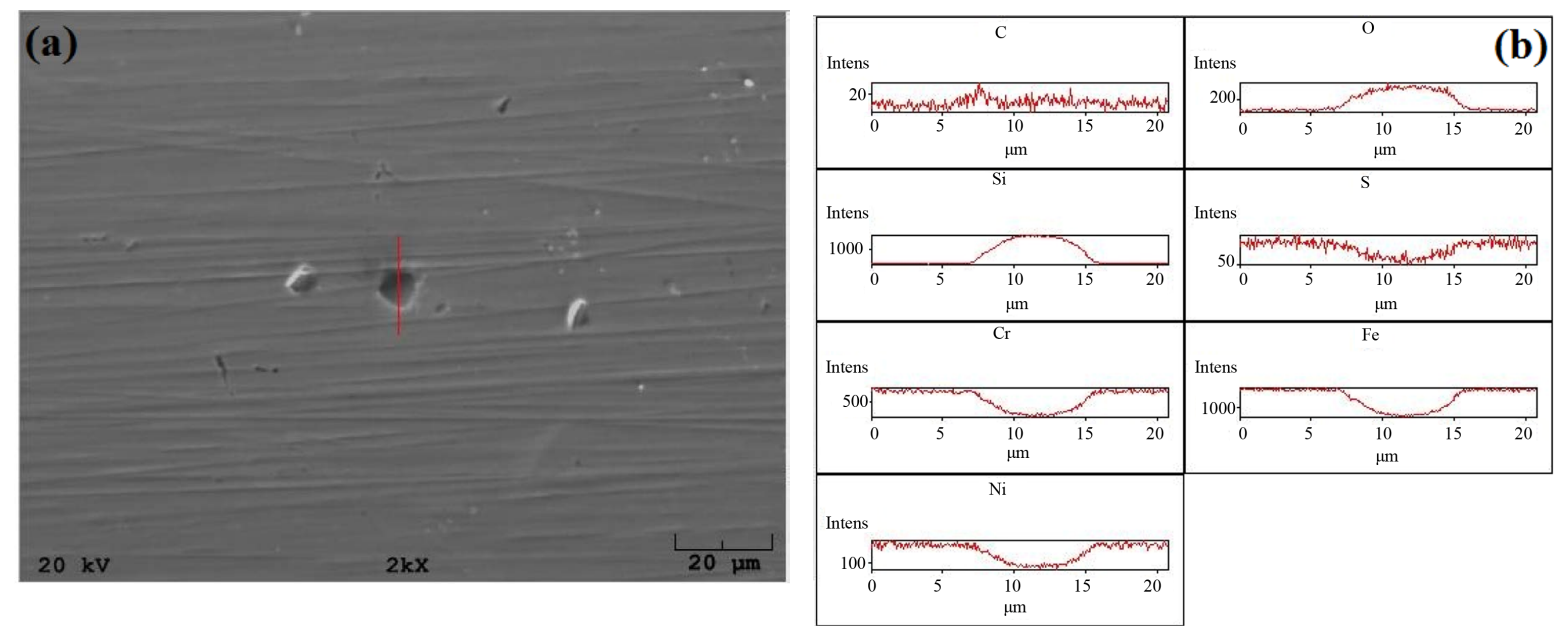

Figure 3. SEM images (a) and EDX analyses (b) of sample of AISI 316 steel at 2000× magnification before the corrosion process.
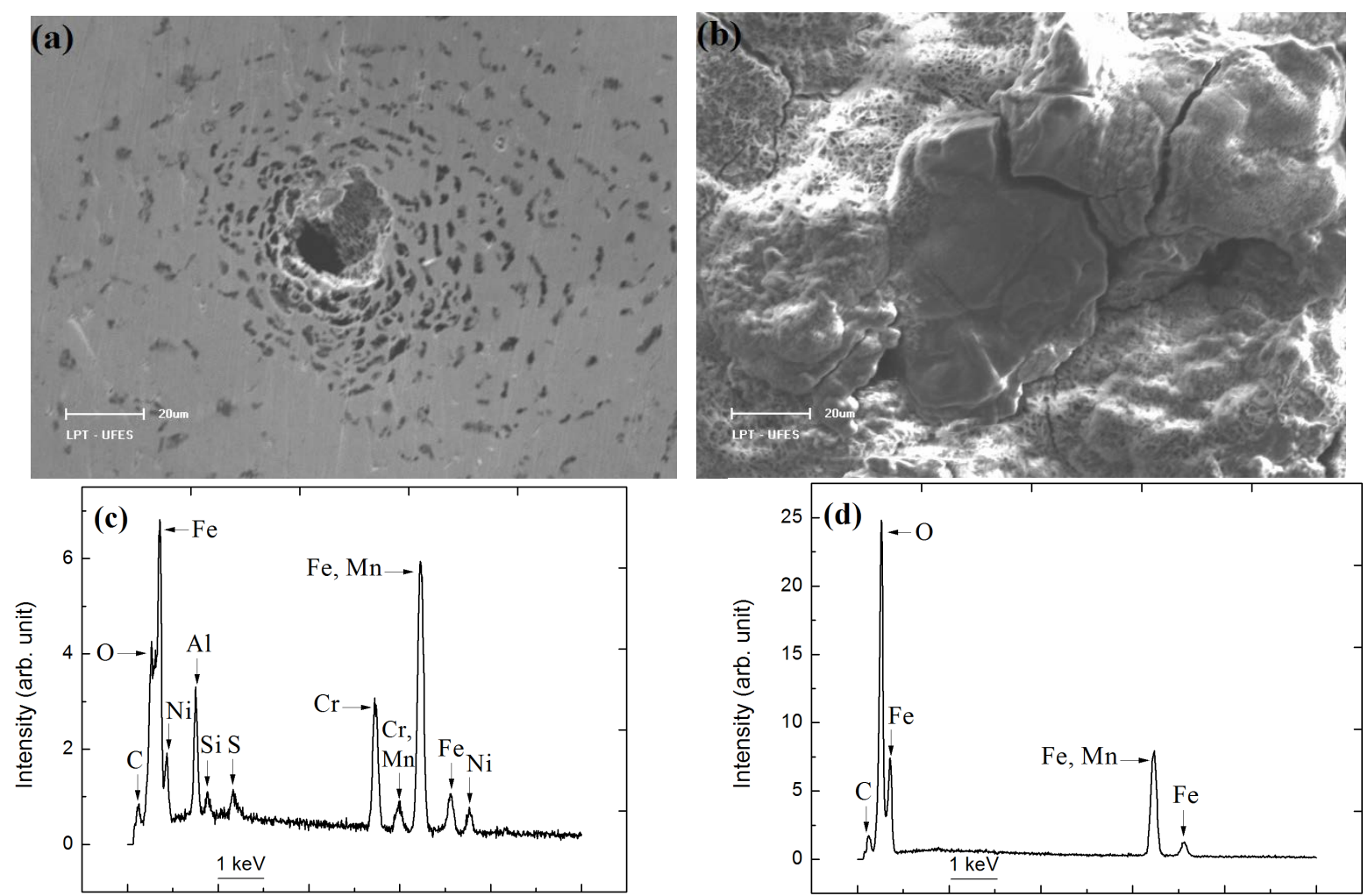

Figure 4. SEM images and EDX analyses of steel samples at $600 \times$ magnification after the corrosion process in the presence of sodium chloride at 3.0 wt.\% solution. (a) (c) AISI 316 stainless steel; (b) (d) AISI 1010 carbon steel.

face is exposed to the corrosive medium and is thus susceptible to widespread corrosion, instead of localised pitting corrosion, as observed in the surface analysis. Additionally, the EDX results (Figure 4(d)) contain no evidence of inclusions containing $\mathrm{Al}$, Si or S, thereby reducing the likelihood of localised pitting corrosion.

\subsection{Electrochemical Investigations}

The electrochemical behaviour of AISI 316 stainless steels and AISI 1010 carbon steel in the presence of chloride ions was investigated using Tafel plots, as shown in Figure 5. From Tafel analysis of the curves, it was 


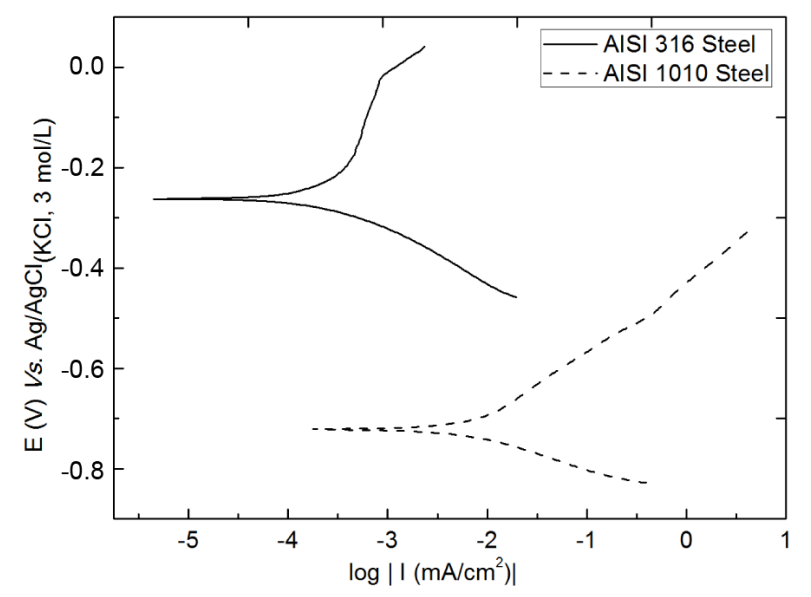

Figure 5. Tafel plots of the AISI 316 stainless steel and AISI 1010 carbon steel in the presence of $3.0 \mathrm{wt} \%$ solution of chloride ions. Temperature $=24^{\circ} \mathrm{C} \pm 1.0^{\circ} \mathrm{C}$; scan rate of 0.5 $\mathrm{mV} \cdot \mathrm{s}^{-1}$.

possible to obtain parameters related to the corrosion of steels, such as corrosion potential $\left(\mathrm{E}_{\text {corr }}\right)$ and polarisation resistance $\left(R_{p}\right)$, which are important for the evaluation of the corrosion data. Anode active regions in which the current density increases with increasing potential are observed in Figure 5 and are consistent with the behaviour of steels. For steel AISI 316, this region begins at $0.15 \mathrm{~V}$ vs. $\mathrm{Ag} / \mathrm{AgCl}_{(\mathrm{KCl}} 3 \mathrm{~mol} / \mathrm{L}$ ), and for AISI 1010 steel, it begins at $-0.45 \mathrm{~V} v$ s. $\mathrm{Ag} / \mathrm{AgCl}_{(\mathrm{KCl}, 3 \mathrm{~mol} / \mathrm{L}) \text {. }}$

Furthermore, the current density increases more sharply with the increase of the potential for AISI 1010 steel, indicating that this steel has less resistance to corrosion steel AISI 316. This finding is in agreement with the results from the literature showing that the composition of steel influences the corrosion behaviour [14] [15]. This active behaviour is caused by the dissolution of the steel in the presence of chloride ion. The steel reacts to form the ferrous chloride, which is hydrolysed to form ferrous hydroxide and hydrochloric acid. This process decreases the $\mathrm{pH}$ of the medium and accelerates the corrosion mechanism [41]. The curves also show a region of potential where capacitive capacitive current exists, which is caused by the charging of the electric double layer. In this region, there is no increase in current density with increasing potential and virtually zero total current, which indicates that there is no breaking of the passive layer present on the steel surface [10]. For AISI 316, that potential range is approximately $1350 \mathrm{mV}$ and is greater than that of AISI 1010 steel, which has an approximately $750 \mathrm{mV}$ range. Thus, the AISI 316 steel has a more stable passive layer (data not shown).

The Tafel plots also show the corrosion resistance of AISI 316 steel compared with AISI 1010 steel, with $-262 \mathrm{mV}$ from $\mathrm{E}_{\text {corr }} v$ s. $\mathrm{Ag} / \mathrm{AgCl}_{(\mathrm{KCl}, 3 \mathrm{~mol} / \mathrm{L})}$ and $-722 \mathrm{mV}$ vs. $\mathrm{Ag} / \mathrm{AgCl}_{(\mathrm{KCl}, 3 \mathrm{~mol} / \mathrm{L})}$, respectively, in accordance with the analysis of potentiodynamic curves. This behaviour is due to the composition of each steel and the corrosion resistance imparted to the AISI 316 steel because of the presence of elements such as chromium and nickel, which are responsible for reducing the susceptibility of steel corrosion due to the possibility of film formation on the steel surface [14] [15].

\subsection{Electrochemical Study of Steels with Benzimidazole Inhibitor}

Tafel curves for the AISI 316 and AISI 1010 steels in $3.0 \mathrm{wt} \%$ chloride ion solution + benzimidazole inhibitor at different concentrations (from 25 ppm to 1000 ppm) are shown in Figure 6. By extrapolating the Tafel plots, values of the electrochemical parameters associated with corrosion processes, such as corrosion potential $\left(E_{\text {corr }}\right)$, corrosion current density $\left(i_{\text {corr }}\right)$ and polarisation resistance $\left(R_{p}\right)$, were obtained. The results of the corrosion inhibition efficiency of the benzimidazole were calculated from the values of the polarisation resistance $\left(R_{p}\right)$ using Equation (1), as shown in the literature [42].

$$
n(\%)=\frac{R p(\text { inhibitor })-R p}{R p(\text { inhibitor })} \times 100
$$


$R_{p}$ (inhibitor) and $R_{p}$ are the polarisation resistance values in the presence or absence of inhibitor, respectively. Table 2 lists the obtained parameters and the corrosion inhibition efficiency $(n)$ of benzimidazole.

Table 2 shows that there was an increase in $R_{p}$ for all concentrations of benzimidazole for both steels, which means that the inhibitor is inhibiting the corrosion reaction. Moreover, the corrosion potential $\left(E_{\text {corr }}\right)$ shifted to more anodic potentials. For both steels, the best inhibition efficiency was observed at an inhibitor concentration of $100 \mathrm{ppm}$, with an efficiency of $71.4 \%$ and $R_{p}=8.93 \mathrm{k} \Omega \cdot \mathrm{cm}^{2}$ for AISI 316 and an efficiency of $51.2 \%$ and $R_{p}$ $=178.60 \Omega \cdot \mathrm{cm}^{2}$ for the AISI 1010 steel.

Khaled [27] used benzimidazole as a corrosion inhibitor for iron in acidic medium and showed that at a concentration of $0.05 \mathrm{~mol} \cdot \mathrm{L}^{-1}$ benzimidazole, which is greater than the concentration used in this paper, the maximum efficiency was $51 \%$. This result shows that the benzimidazole effectively acted as an inhibitor for both the steel and the AISI 316 and AISI 1010 steels in corrosive environment studied. Tang et al. [42] used benzimidazole derivatives, such as 2-aminomethyl benzimidazole, as corrosion inhibitors for mild carbon steel in acid medium and showed a maximum corrosion inhibition efficiency of $74 \%$ at the highest concentration studied (0.002 $\mathrm{mol} \cdot \mathrm{L}^{-1}$ ). Because the molecular structure of this inhibitor provides more adsorption sites compared with benzimidazole and is a molecule of greater steric body that can better cover the surface of the steel, it should be noted that benzimidazole showed a maximum inhibition efficiency of $71.4 \%$ for AISI 316 steel, which is very close to the maximum obtained by Tang et al. [42]. As observed in this study, benzimidazole showed a better inhibition for AISI 316 steel, and this behaviour was observed in almost all of the inhibitor concentrations studied.

According to the literature, benzimidazole derivatives protect the steel surface by adsorption to form an insoluble complex with Fe (II) and the segments of these derivatives that are longer than benzimidazole increase the molecule inhibition efficiency [42]. The adsorption mechanism is due to the lone pair electrons and the $\pi$
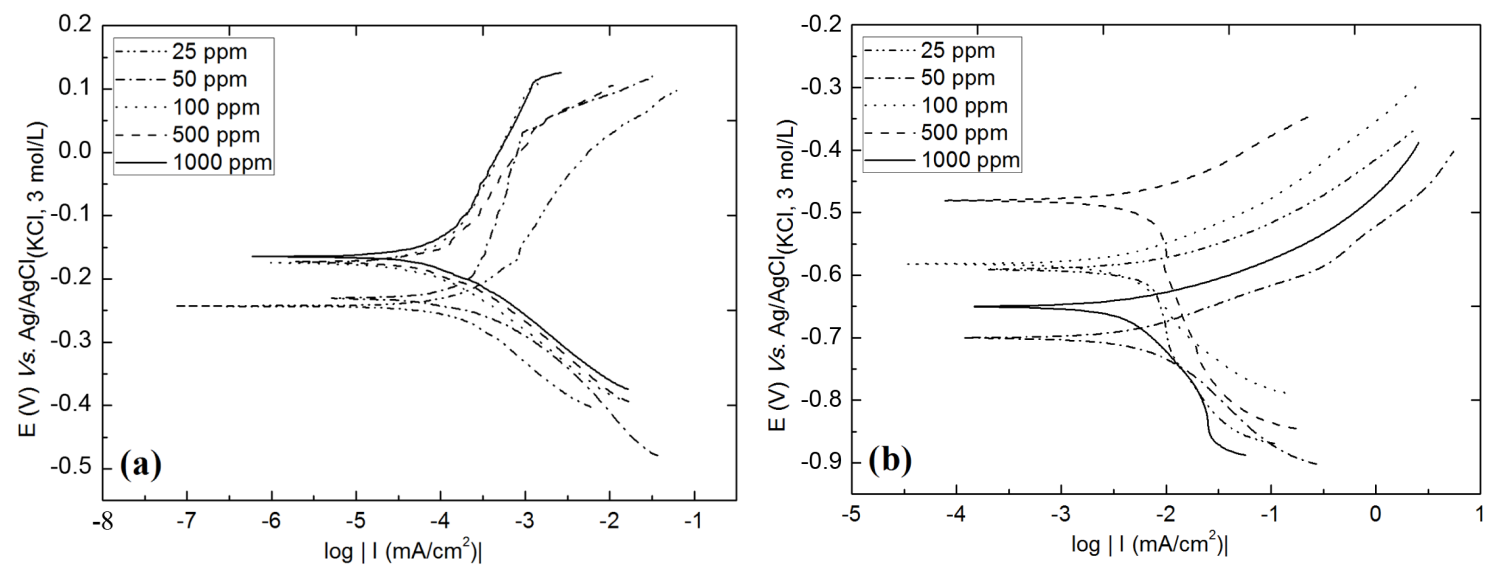

Figure 6. Tafel plots of steel in the middle of chloride ion solution at $3.0 \mathrm{wt} \% 24^{\circ} \mathrm{C} \pm 1.0^{\circ} \mathrm{C}$ at different concentrations of benzimidazole. (a) AISI 316 stainless steel and (b) AISI 1010 carbon steel.

Table 2. Results obtained from Tafel plots for AISI 316 stainless steel and AISI 1010 carbon steel immersed in 3.0 wt $\%$ chloride ion solution at $24^{\circ} \mathrm{C} \pm 1.0^{\circ} \mathrm{C}$ in the presence of different concentrations of benzimidazole (from 0 ppm to 1000 $\mathrm{ppm})$.

\begin{tabular}{ccccccc}
\hline \multirow{2}{*}{ Benzimidazole } & \multicolumn{3}{c}{ AISI 316} & \multicolumn{3}{c}{ AISI 1010} \\
\cline { 2 - 7 } & $E_{\text {corr }}(\mathrm{mV})$ & $R p\left(\mathrm{k} \Omega \cdot \mathrm{cm}^{2}\right)$ & $n(\%)$ & $E_{\text {corr }}(\mathrm{mV})$ & $R p\left(\Omega \cdot \mathrm{cm}^{2}\right)$ & $n(\%)$ \\
\hline $0 \mathrm{ppm}$ & -262 & 2.55 & - & -722 & 87.14 & - \\
$25 \mathrm{ppm}$ & -243 & 4.28 & 40.42 & -591 & 89.29 & 2.41 \\
$50 \mathrm{ppm}$ & -231 & 3.78 & 32.54 & -700 & 142.90 & 39.02 \\
$100 \mathrm{ppm}$ & -174 & 8.93 & 71.44 & -582 & 178.60 & 51.21 \\
$500 \mathrm{ppm}$ & -173 & 7.15 & 64.34 & -480 & 110.50 & 21.14 \\
$1000 \mathrm{ppm}$ & -165 & 5.53 & 53.89 & -650 & 94.58 & 7.87 \\
\hline
\end{tabular}


electrons of the aromatic ring that are present in the inhibitor molecule and occupy the empty d orbitals of Fe atoms, forming a protective film on the steel surface [43] [44]. It is also possible that inhibitor packaging products of corrosion may hinder the diffusion of aggressive species to the steel surface [42]. Such phenomena may have been responsible for the results of corrosion inhibition by benzimidazole. However, the lower inhibition efficiency obtained for AISI 1010 steel compared with AISI 316 steel suggests that the benzimidazole may have failed to adsorb to the surface of this steel, which indicates a less effective and/or weaker adsorption onto the surface. Another suggestion may be the resulting geometry of the packing of inhibitor molecules, which leaves portions of the surface exposed to the corrosive environment. Additionally, the smaller steric body of this molecule may not have protected the entire surface. For example, in studies conducted by Khaled and Amin [43] using the thiazole derivative 2-Amino-4-(p-tolyl) thiazole, which has a larger steric body than benzimidazole, the maximum inhibition efficiency was $95.2 \%$ for carbon steel.

\subsection{Electrochemical Study of Steels with Imidazole Inhibitor}

Figure 7 shows the Tafel plots of AISI 316 and AISI 1010 steels obtained from the solution of $3.0 \mathrm{wt} \%$ chloride ions in the presence of imidazole inhibitor at different concentrations (from 25 ppm to $1000 \mathrm{ppm}$ ). The Tafel plots show that there is a decrease in the current density in the presence of imidazole inhibitor. Moreover, there was a change of corrosion potential $\left(E_{\text {corr }}\right)$ to more anodic values.

The obtained parameters and the corrosion inhibition efficiency $(n)$ of imidazole are shown in Table 3 . For both steels, the inhibitor concentration that showed the best inhibition efficiency was $50 \mathrm{ppm}$, with an efficiency of $\sim 96 \%$, and $R_{p}=63.18 \mathrm{k} \Omega \cdot \mathrm{cm}^{2}$ for the AISI 316 stainless steel and an efficiency of $\sim 73 \%$ and $R_{p}=325.10$ $\Omega \cdot \mathrm{cm}^{2}$ for the AISI 1010 carbon steel.
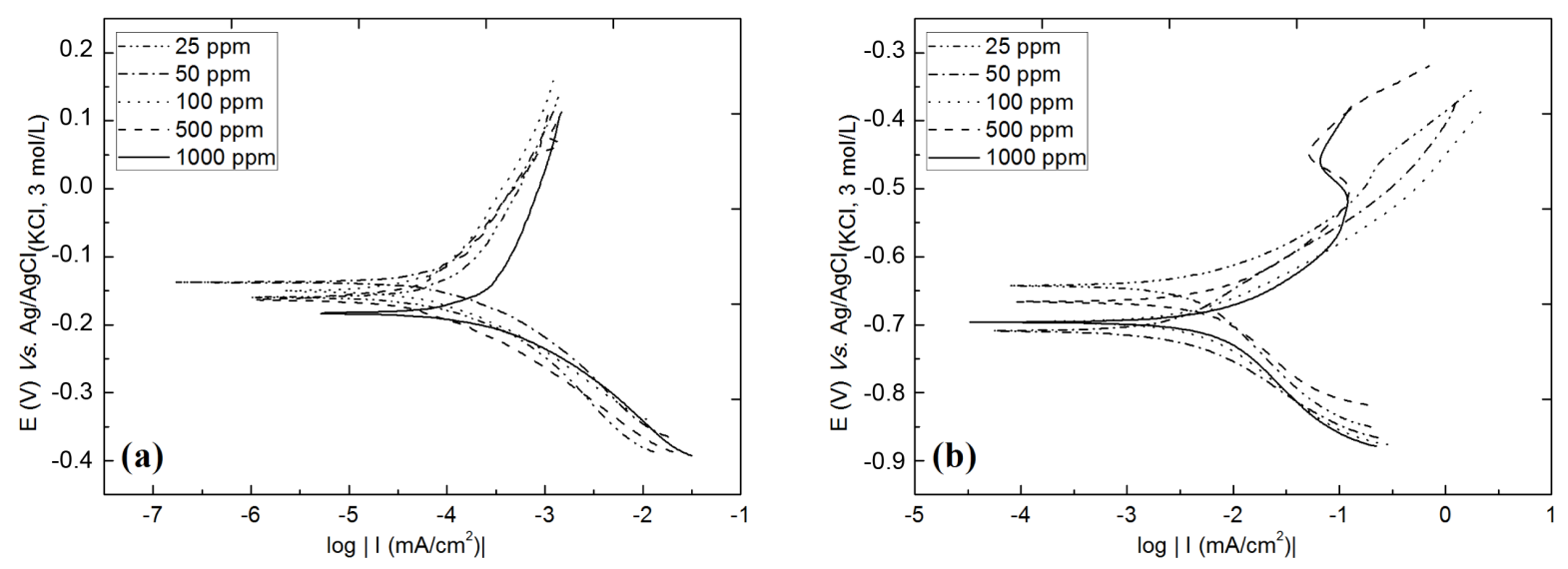

Figure 7. Tafel plots of steel in $3.0 \mathrm{wt} \%$ chloride ion solution at $24^{\circ} \mathrm{C} \pm 1.0^{\circ} \mathrm{C}$ with different concentrations of imidazole. (a) AISI 316 stainless steel and (b) AISI 1010 carbon steel.

Table 3. Results obtained from Tafel plots for AISI 316 and AISI 1010 steels immersed in 3.0 wt $\%$ chloride ion solution at $24^{\circ} \mathrm{C} \pm 1.0^{\circ} \mathrm{C}$ in the presence of different concentrations of imidazole (from $0 \mathrm{ppm}$ to $1000 \mathrm{ppm}$ ).

\begin{tabular}{ccccccc}
\hline & \multicolumn{3}{c}{ AISI 316} & \multicolumn{3}{c}{ AISI 1010} \\
\cline { 2 - 7 } Imidazole & $E_{\text {corr }}(\mathrm{mV})$ & $R p\left(\mathrm{k} \Omega \cdot \mathrm{cm}^{2}\right)$ & $n(\%)$ & $E_{\text {corr }}(\mathrm{mV})$ & $R p\left(\Omega \cdot \mathrm{cm}^{2}\right)$ & $n(\%)$ \\
\hline $0 \mathrm{ppm}$ & -262 & 2.55 & - & -722 & 87.14 & - \\
$25 \mathrm{ppm}$ & -160 & 15.96 & 84.02 & -643 & 187.20 & 53.45 \\
$50 \mathrm{ppm}$ & -138 & 63.18 & 95.96 & -709 & 325.10 & 73.20 \\
$100 \mathrm{ppm}$ & -150 & 13.60 & 81.25 & -696 & 176.70 & 50.68 \\
$500 \mathrm{ppm}$ & -164 & 18.92 & 86.52 & -666 & 101.00 & 13.72 \\
$1000 \mathrm{ppm}$ & -183 & 3.02 & 15.56 & -696 & 113.40 & 23.16 \\
\hline
\end{tabular}


Zhang et al. [31], using imidazole as a corrosion inhibitor for iron in acidic medium, achieved a maximum efficiency of $79.6 \%$ at a concentration of $0.1 \mathrm{~mol} \cdot \mathrm{L}^{-1}$ inhibitor, which was higher than the concentration used in this study here. Another study by He et al. [45] that used imidazole to inhibit corrosion in aluminium found a maximum efficiency of $79.4 \%$ at an imidazole concentration of $0.014 \mathrm{~mol} \cdot \mathrm{L}^{-1}$. These results indicate that the imidazole proved effective in inhibiting corrosion for the two steels studied in this work and that higher inhibition efficiencies were obtained for AISI 316 stainless steel compared with AISI 1010 carbon steel at almost all of the inhibitor concentrations studied.

The results showed that imidazole showed better corrosion inhibition efficiency than did benzimidazole. The imidazole molecule has a planar aromatic ring containing two $\mathrm{N}$ heteroatoms. According to Mendes et al. [36], this molecule can be adsorbed by the imidazole ring, parallel to the surface of the metallic material, which may be one reason for the better efficiency of inhibition. Thus, it is suggested the imidazole molecules covered more of the metal surface due to a better compression between them, thus resulting in higher corrosion inhibition efficiency.

\section{Conclusions}

The analysis performed using XRD showed that the different phases are present in the steels and affect corrosion resistance. The SEM and EDX techniques make it possible to identify and determine the composition of the regions that are more susceptible to corrosion, such as inclusions in the steels. These techniques also allow for the further characterisation of the type of corrosion suffered by each steel.

Electrochemical studies have shown that at any inhibitor concentration (25 ppm to $1000 \mathrm{ppm}$ ), there was an increase of the polarisation resistance of both steels, indicating that there was an increase in corrosion resistance.

The best corrosion inhibition result for AISI 316 steel and AISI 1010 steel using benzimidazole was obtained at an inhibitor concentration of $100 \mathrm{ppm}$, and the inhibition efficiency values were $\sim 71 \%$ and $~ 51 \%$, respectively. When imidazole was used as the inhibitor, the best corrosion inhibition was obtained for both steels using imidazole at an inhibitor concentration of $50 \mathrm{ppm}$, with inhibition efficiency values of $\sim 96 \%$ and $\sim 73 \%$, respectively.

\section{Acknowledgements}

The authors thank FAPES No 61612626/2013, CAPES, CNPq, UFES, PETROBRAS, IFES, and LPT-UFES TRICORRMAT-UFES.

\section{References}

[1] Groysman, A. and Brodsky, N. (2006) Corrosion and Quality. Accreditation and Quality Assurance, 10, 537-542. http://dx.doi.org/10.1007/s00769-005-0034-3

[2] Almeida, M. (2005) Minimisation of Steel Atmospheric Corrosion: Updated Structure of Intervention. Progress in Organic Coatings, 54, 81-90. http://dx.doi.org/10.1016/j.porgcoat.2005.01.007

[3] Hao, L., Zhang, S., Dong, J. and Ke, W. (2011) Atmospheric Corrosion Resistance of MnCuP Weathering Steel in Simulated Environments. Corrosion Science, 53, 4187-4192. http://dx.doi.org/10.1016/j.corsci.2011.08.028

[4] Shifler, D.A. (2005) Understanding Material Interactions in Marine Environments to Promote Extended Structural Life. Corrosion Science, 47, 2335-2352. http://dx.doi.org/10.1016/j.corsci.2004.09.027

[5] Kage, I., Matsui, K. and Kawabata, F. (2005) Minimum Maintenance Steel Plates and Their Application Technologies for Bridge-Life Cycle Cost Reduction Technologies with Environmental Safeguards for Preserving Social Infrastructure Assets. JFE Technical Report, 5, 31-37.

[6] Tsutsumi, Y., Nishikata, A. and Tsuru, T. (2007) Pitting Corrosion Mechanism of Type 304 Stainless Steel under a Droplet of Chloride Solutions. Corrosion Science, 49, 1394-1407. http://dx.doi.org/10.1016/j.corsci.2006.08.016

[7] Laycock, N.J. and Newman, R.C. (1997) Localised Dissolution Kinetics, Salt Films and Pitting Potentials. Corrosion Science, 39, 1771-1790. http://dx.doi.org/10.1016/S0010-938X(97)00049-8

[8] Newman, R.C. (2001) Understanding the Corrosion of Stainless Steel. Corrosion, 57, 1030-1041. http://dx.doi.org/10.5006/1.3281676

[9] Martini, E.M.A. and Muller, I.L. (2000) Characterization of the Film formed on Iron in Borate Solution by Electrochemical Impedance Spectroscopy. Corrosion Science, 42, 443-454. http://dx.doi.org/10.1016/S0010-938X(99)00064-5 
[10] Pistorius, P.C. and Burstein G.T. (1992) Metastable Pitting Corrosion of Stainless Steel and the Transition to Stability. Philosophical Transactions of the Royal Society A, 341, 531-559. http://dx.doi.org/10.1098/rsta.1992.0114

[11] Kondo, Y. (1989) Prediction of Fatigue Crack Initiation Life Based on Pit Growth. Corrosion, 45, 7-11. http://dx.doi.org/10.5006/1.3577891

[12] Turnbull, A., Mccartney, L.N. and Zhou, S. (2006) A Model to Predict the Evolution of Pitting Corrosion and the Pit-to-Crack Transition Incorporating Statistically Distributed Input Parameters. Corrosion Science, 48, 2084-2105. http://dx.doi.org/10.1016/j.corsci.2005.08.010

[13] Baddoo, N.R. (2008) Stainless Steel in Construction: A Review of Research, Applications, Challenges and Opportunities. Journal of Constructional Steel Research, 64, 1199-1206. http://dx.doi.org/10.1016/j.jcsr.2008.07.011

[14] Malik, A.U., Siddiqi, N., Ahmad, S. and Andijani, I.N. (1995) The Effect of Dominant Alloy Additions on the Corrosion Behaviour of Some Conventional and High Alloy Stainless Steels in Seawater. Corrosion Science, 37, 1521-1535. http://dx.doi.org/10.1016/0010-938X(95)00043-J

[15] Lippold, J.C. and Kotecki, D.J. (2005) Welding Metallurgy of Stainless Steel. Wiley-Intercience, New Jersey.

[16] Avci, R., Davis, B.H., Wolfenden, M.L., Beech, I.B., Lucas, K. and Paul, D. (2013) Mechanism of MnS-Mediated Pit Initiation and Propagation in Carbon Steel in an Anaerobic Sulfidogenic Media. Corrosion Science, 76, 267-274. http://dx.doi.org/10.1016/j.corsci.2013.06.049

[17] Rangaraju, R.R., Raja, K.S., Panday, A. and Misra, M. (2010) Low-Cost Photoelectrocatalyst Based on a Nanoporous Oxide Layer of Low-Carbon Steel. Journal of Physics D: Applied Physics, 43, Article ID: 445301. http://dx.doi.org/10.1088/0022-3727/43/44/445301

[18] Ormellese, M., Lazzari, L., Goidanich, S., Fumagalli, G. and Brenna, A. (2009) A Study of Organic Substances as Inhibitors for Chloride-Induced Corrosion in Concrete. Corrosion Science, 51, 2959-2968. http://dx.doi.org/10.1016/j.corsci.2009.08.018

[19] Fekry, A.M. and Ameer, M.A. (2010) Corrosion Inhibition of Mild Steel in Acidic Media Using Newly Synthesized Heterocyclic Organic Molecules. International Journal of Hydrogen Energy, 35, 7641-7651. http://dx.doi.org/10.1016/j.ijhydene.2010.04.111

[20] Lunarska, E. and Chernyayeva, O. (2006) Effect of Corrosion Inhibitors on Hydrogen Uptake by Al from NaOH Solution. International Journal of Hydrogen Energy, 31, 285-293. http://dx.doi.org/10.1016/j.ijhydene.2005.04.051

[21] Zucchi, F., Trabanelli, G., Frignani, A. and Zucchini, M. (1978) The Inhibition of Stress Corrosion Cracking of Stainless Steels in Chloride Solutions. Corrosion Science, 18, 87-95. http://dx.doi.org/10.1016/S0010-938X(78)80078-X

[22] Galal, A., Atta, N.F. and Al-Hassan, M.H.S. (2005) Effect of Some Thiophene Derivatives on the Electrochemical Behaviour of AISI 316 Austenitic Stainless Steel in Acidic Solutions Containing Chloride Ions I. Molecular Structure and Inhibition Efficiency Relationship. Materials Chemistry and Physics, 89, 38-48. http://dx.doi.org/10.1016/j.matchemphys.2004.08.019

[23] Goudarzi, N. and Farahani, H. (2014) Investigation on 2-Mercaptobenzothiazole Behaviour as Corrosion Inhibitor for 316-Stainless Steel in Acidic Media. Anti-Corrosion Methods and Materials, 61, 20-26. http://dx.doi.org/10.1108/ACMM-11-2012-1223

[24] Granero, M.F.L., Matai, P.H.L.S., Aoki, I.V. and Guedes, I.C. (2009) Dodigen 213-N as Corrosion Inhibitor for ASTM 1010 Mild Steel in 10\% HCl. Journal of Applied Electrochemistry, 39, 1199-1205. http://dx.doi.org/10.1007/s10800-009-9785-6

[25] Duda, Y., Govea-Rueda, R., Galicia, M., Beltrán, H.I. and Zamudio-Rivera, L.S. (2005) Corrosion Inhibitors: Design, Performance and Computer Simulations. The Journal of Physical Chemistry B, 109, 22674-22684. http://dx.doi.org/10.1021/jp0522765

[26] Kuznetsov, Y.I. and Kazansky, L.P. (2008) Physicochemical Aspects of Metal Protection by Azoles as Corrosion Inhibitors. Russian Chemical Reviews, 77, 219-232. http://dx.doi.org/10.1070/RC2008v077n03ABEH003753

[27] Khaled, K.F. (2003) The Inhibition of Benzimidazole Derivatives on Corrosion of Iron in 1M HCl Solutions. Electrochimica Acta, 48, 2493-2503. http://dx.doi.org/10.1016/S0013-4686(03)00291-3

[28] Wang, L. (2001) Evaluation of 2-Mercaptobenzimidazole as Corrosion Inhibitor for Mild Steel in Phosphoric Acid. Corrosion Science, 43, 2281-2289. http://dx.doi.org/10.1016/S0010-938X(01)00036-1

[29] Popova, A., Christov, M. and Deligeorgiev, T. (2003) Influence of the Molecular Structure on the Inhibitor Properties of Benzimidazole Derivatives on Mild Steel Corrosion in 1 M Hydrochloric Acid. Corrosion, 59, 756-764. http://dx.doi.org/10.5006/1.3277604

[30] Aljourani, J., Raeissi, K. and Golozar, M.A. (2009) Benzimidazole and Its Derivatives as Corrosion Inhibitors for Mild Steel in 1M HCl Solution. Corrosion Science, 51, 1836-1843. http://dx.doi.org/10.1016/j.corsci.2009.05.011 
[31] Zhang, Z., Chen, S., Li, Y., Li, S. and Wanga, L. (2009) A Study of the Inhibition of Iron Corrosion by Imidazole and Its Derivatives Self-Assembled Films. Corrosion Science, 51, 291-300. http://dx.doi.org/10.1016/j.corsci.2008.10.040

[32] Curkovic, H.O., Stupnišek-lisac, E. and Takenouti, H. (2010) The Influence of pH Value on the Efficiency of Imidazole Based Corrosion Inhibitors of Copper. Corrosion Science, 52, 398-405. http://dx.doi.org/10.1016/j.corsci.2009.09.026

[33] Zhang, D.Q., Gao, L.X. and Zhou, G.D. (2004) Inhibition of Copper Corrosion in Aerated Hydrochloric Acid Solution by Heterocyclic Compounds Containing a Mercapto Group. Corrosion Science, 46, 3031-3040. http://dx.doi.org/10.1016/j.corsci.2004.04.012

[34] Popova, A., Sokolova, E., Raicheva, S. and Christov, M. (2003) AC and DC Study of the Temperature Effect on Mild Steel Corrosion in Acid Media in the Presence of Benzimidazole Derivatives. Corrosion Science, 45, 33-58. http://dx.doi.org/10.1016/S0010-938X(02)00072-0

[35] Kokalj, A. (2013) Formation and Structure of Inhibitive Molecular Film of Imidazole on Iron Surface. Corrosion Science, 68, 195-203. http://dx.doi.org/10.1016/j.corsci.2012.11.015

[36] Mendes, J.O., Silva, E.C. and Rocha, A.B. (2012) On the Nature of Inhibition Performance of Imidazole on Iron Surface. Corrosion Science, 57, 254-259. http://dx.doi.org/10.1016/j.corsci.2011.12.011

[37] Mousavi, M., Mohammadalizadeh, M. and Khosravan, A. (2011) Theoretical Investigation of Corrosion Inhibition Effect of Imidazole and Its Derivatives on Mild Steel Using Cluster Model. Corrosion Science, 53, 3086-3091. http://dx.doi.org/10.1016/j.corsci.2011.05.034

[38] ASM International Handbook Committee (1990) Volume 1: Properties and Selection: Irons, Steels and High-Performance Alloys. ASM International, Ohio, 150.

[39] Li, Y., Hu, R.G., Wang, J.R., Huang, Y.X. and Lin, C.-J. (2009) Corrosion Initiation of Stainless Steel in HCl Solution Studied Using Electrochemical Noise and in Situ Atomic Force Microscope. Electrochimica Acta, 54, 7134-7140. http://dx.doi.org/10.1016/j.electacta.2009.07.042

[40] Gammer, K., Rosner, M., Poeckl, G. and Hutter, H. (2003) AES and SIMS Analysis of Non-Metallic Inclusions in a Low-Carbon Chromium-Steel. Analytical and Bioanalytical Chemistry, 376, 255-259. http://dx.doi.org/10.1007/s00216-003-1851-z

[41] Yang, Y.Z., Jiang, Y.M. and Li, J. (2013) In Situ Investigation of Crevice Corrosion on UNS S32101 Duplex Stainless Steel in Sodium Chloride Solution. Corrosion Science, 76, 163-169. http://dx.doi.org/10.1016/j.corsci.2013.06.039

[42] Tang, Y., Zhang, F., Hu, S., Cao, Z., Wu, Z. and Jing, W. (2013) Novel Benzimidazole Derivatives as Corrosion Inhibitors of Mild Steel in the Acidic Media. Part I: Gravimetric, Electrochemical, SEM and XPS studies. Corrosion Science, 74, 271-282. http://dx.doi.org/10.1016/j.corsci.2013.04.053

[43] Khaled, K.F. and Amin, M.A. (2009) Corrosion Monitoring of Mild Steel in Sulphuric Acid Solutions in Presence of Some Triazole Derivatives-Molecular Dynamics, Chemical and Electrochemical Studies. Corrosion Science, 51, 1964-1975. http://dx.doi.org/10.1016/j.corsci.2009.05.023

[44] Negma, N.A., Kandile, N.G., Badr, E.A. and Mohammed, M.A. (2012) Gravimetric and Electrochemical Evaluation of Environmentally Friendly Nonionic Corrosion Inhibitors for Carbon Steel in 1 M HCl. Corrosion Science, 65, 94-103. http://dx.doi.org/10.1016/j.corsci.2012.08.002

[45] He, X., Jiang, Y., Li, C., Wang, W., Hou, B. and Wu, L. (2014) Inhibition Properties and Adsorption Behaviour of Imidazole and 2-Phenyl-2-Imidazoline on AA5052 in 1.0 M HCl Solution. Corrosion Science, 83, 124-136. http://dx.doi.org/10.1016/j.corsci.2014.02.004 
Scientific Research Publishing (SCIRP) is one of the largest Open Access journal publishers. It is currently publishing more than 200 open access, online, peer-reviewed journals covering a wide range of academic disciplines. SCIRP serves the worldwide academic communities and contributes to the progress and application of science with its publication.

Other selected journals from SCIRP are listed as below. Submit your manuscript to us via either submit@scirp.org or Online Submission Portal.
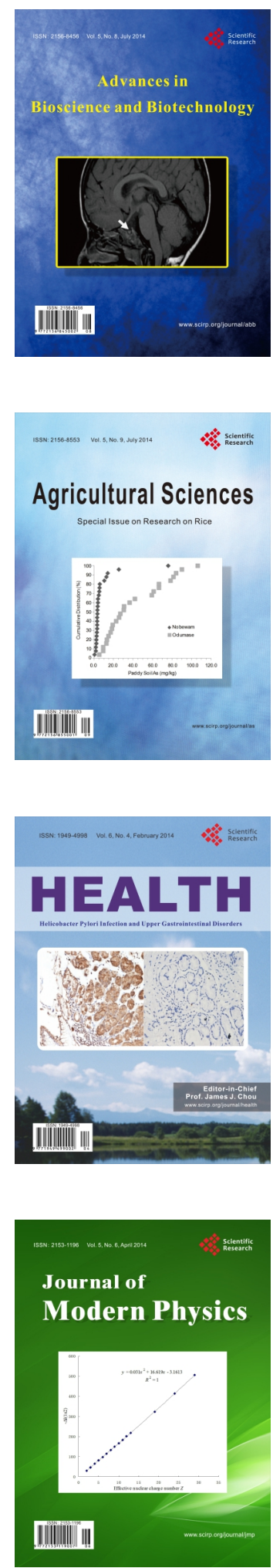
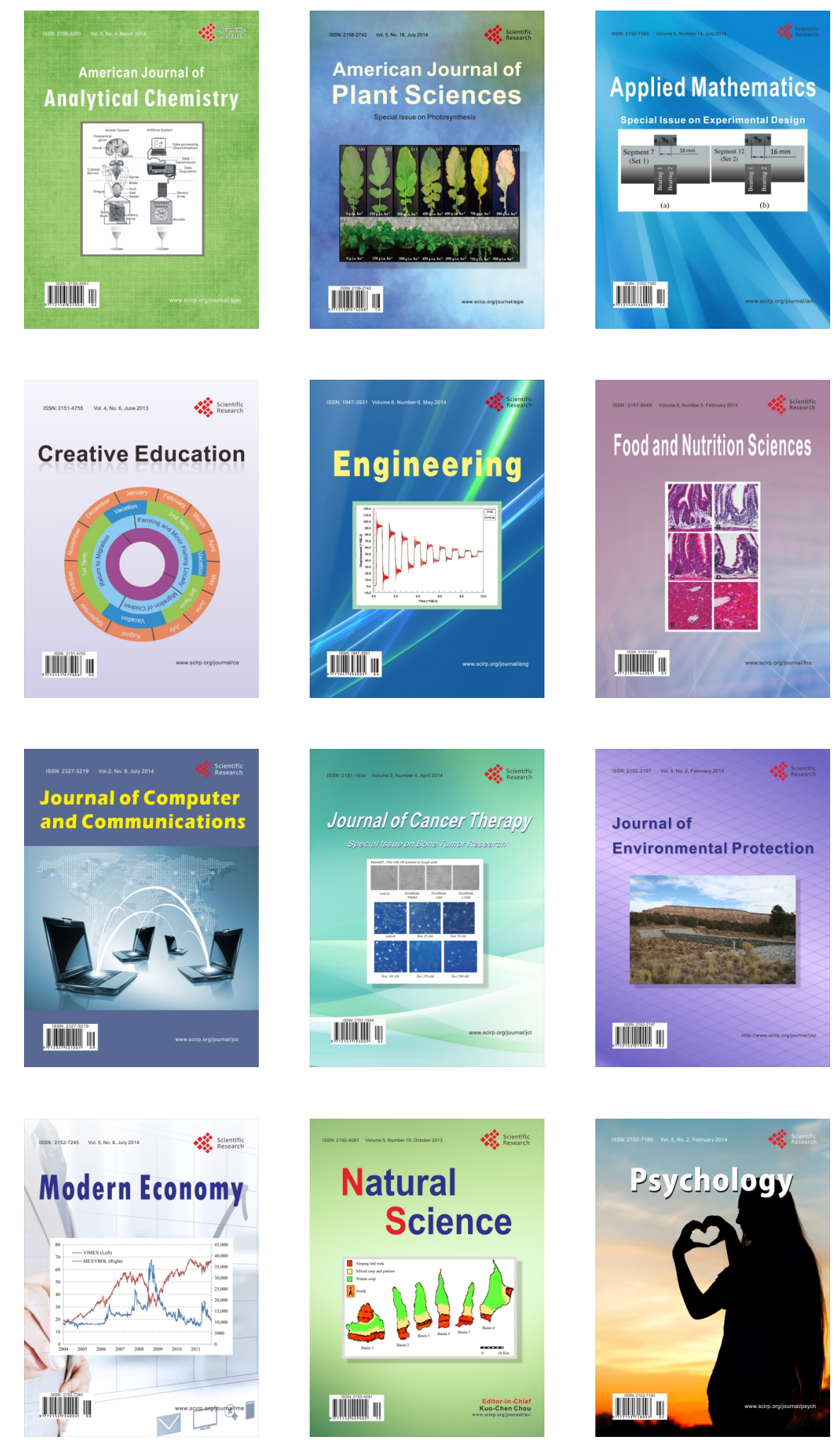